\section{IOPEN ACCESS}

\section{Received August 27, 2019 \\ Revised October 21, 2019}

Accepted October 21, 2019

\author{
Yeongkwon Yun ${ }^{1,{ }^{\dagger}}$, Boin Lee ${ }^{2,{ }^{\dagger}}$, Kimun Kwon $^{1}$, Sejoo Kang ${ }^{1}$, Eunmi Oh ${ }^{2}$, \\ and Young Min $\mathrm{Choi}^{2, *}$ \\ ${ }^{1}$ Korea Institute for Animal Products Quality Evaluation, Sejong 30100, Korea \\ ${ }^{2}$ Department of Animal Sciences, Kyungpook National University, Sangju 37224, \\ Korea
}

\footnotetext{
*Corresponding author : Young Min Choi Department of Animal Sciences, Kyungpook National University, Sangju 37224, Korea Tel: +82-54-530-1232

Fax: +82-54-530-1229

E-mail: ymchoi1@knu.ac.kr

*ORCID

Yeongkwon Yun

https://orcid.org/0000-0002-8374-3525 Boin Lee

https://orcid.org/0000-0001-7745-9766

Kimun Kwon

https://orcid.org/0000-0001-8191-9016

Sejoo Kang

https://orcid.org/0000-0003-1192-3399

Eunmi Oh

https://orcid.org/0000-0002-1595-7396

Young Min Choi

https://orcid.org/0000-0003-2376-7784

† These authors contributed equally to this work.
}

\begin{abstract}
The objectives of this study was to compare palatability changes of the longissimus thoracis (LT) and vastus lateralis (VL) muscles of Hanwoo steers from different beef quality grades $\left(1^{+}\right.$and 1$)$ during $28 \mathrm{~d}$ of wet-aging in order to improve the utilization of the VL muscle as a steak. The VL muscle showed a higher collagen content and a lower intramuscular fat content than the LT muscle $(p<0.05)$. As expected, the Warner-Bratzler shear force value was greater in the LT 1 grade (LT-1) muscle than the LT $-1^{+}$muscle $(\mathrm{p}<0.05)$; whereas no difference was observed between the grades in the $\mathrm{VL}$ muscle at $24 \mathrm{~h}$ postmortem. Compared to $0 \mathrm{~d}$ of aging, tenderness scores significantly increased after 14 and $21 \mathrm{~d}$ of aging in the LT and VL muscles, respectively $(\mathrm{p}<0.05)$. Additionally, there was no difference in tenderness score between the VL- $1^{+}$aged for 21 $\mathrm{d}$ and the LT- 1 at $24 \mathrm{~h}$ postmortem, although tenderness score was greater in the LT than the $\mathrm{VL}$ at each period $(\mathrm{p}<0.05)$. Moreover, the $\mathrm{VL}-1^{+}$steak exhibited a higher tenderness score than the VL-1 steak at 21 and $28 \mathrm{~d}$ of aging $(\mathrm{p}<0.05)$. On the other hand, the effect of aging time on juiciness and flavor in the VL muscle was somewhat limited unlike the LT muscle. Taken together, the VL muscle requires a longer aging time than the LT muscle to improve consumer preference. Considering the tenderness, using a higher quality grade for aging is more useful in the VL muscle.
\end{abstract}

Keywords sensory quality, longissimus thoracis muscle, vastus lateralis muscle, beef quality grade, wet-aging

\section{Introduction}

With the development of economy and society, the interest of many consumers has been more focused on food quality especially eating quality characteristics. Among the eating quality characteristics, which include tenderness, juiciness, and flavor of meat and meat products, tenderness has been considered as the most important determinant

(C) Korean Society for Food Science of Animal Resources. This is an open access article distributed under the terms of the Creative Commons Attribution Non-Commercial License (http://creativecommons.org/licences/by-nc/3.0) which permits unrestricted non-commercial use, distribution, and reproduction in any medium, provided the original work is properly cited. 
of sensory quality traits (Hulankova et al., 2018). Thus, numerous researchers have studied the most frequently about factors that influencing tenderness variation of cooked beef in order to improve tenderness and to ensure the consistency of eating quality (Hulankova et al., 2018; Koohmaraie et al., 2002; Lee et al., 2018).

The extent of marbling or intramuscular fat (IMF) content is one of the pivotal factors that influence tenderness variation (Lee et al., 2019; Smith et al., 1988). Lee et al. (2018) reported the Korean beef quality grades mainly assessed by the extent of marbling was positively correlated with sensory tenderness, and the $1^{++}$grade (marbling scores 8 and 9 ) loin was tenderer than the $1^{+}$(marbling scores 6 and 7) and 1 grade (marbling scores 4 and 5) loins. Additionally, considerable variations in sensory tenderness and Warner-Bratzler shear force (WBS) value exist among beef steaks from different muscles (Nair et al., 2019). It is well known that round muscles, including the vastus lateralis (VL) muscle, are primarily responsible for locomotion (Nair et al., 2019). Thus, beef steaks from round muscles tend to exhibit tougher and inconsistent tenderness, resulting in a lower consumer acceptability compared to steaks from the longissimus thoracis (LT) muscle (Kolle et al., 2004). In this sense, the meat industry is consistently striving to improve tenderness of beef round in order to make a highervalued cut, like loin and rib (Anderson et al., 2012).

Postmortem aging is a common industrial method to improve sensory quality characteristics, especially tenderness. Wetaging, whereby beef cuts are aged in a vacuum sealed plastic pouch at refrigeration temperature, is the most common approach in the meat industry, especially in the USA and Australia, although steaks from wet-aged beef exhibited lower scores of sensory tenderness and flavor intensity compared to steaks from dry-aged beef (Berger et al., 2018). Huff-Lonergan and Lonergan (2005) and Nair et al. (2019) suggested that during the wet-aging process, beef steaks from the LT muscle exhibited a dramatic improvement in palatability, especially tenderness. This improvement in sensory quality was associated with biochemical and structural changes of the LT muscle during postmortem aging period, and these changes in the LT muscle are well-characterized (Huff-Lonergan and Lonergan, 2005; Nair et al., 2019). However, there is a lack of precise information on when and how the sensory quality traits of beef round, especially the VL muscle, are significantly changed during the aging period, although a lower consumer preference for the VL muscle could be improved through postmortem aging as a higher-valued cut.

According to Lepper-Blilie et al. (2016), the aging time for the improvement of sensory tenderness can vary depending on the bovine marbling score and beef quality grade based on the USDA grading system. In Hanwoo steer, little is known regarding the effect of beef quality grade on sensory quality characteristics of wet-aged steaks from the LT and VL muscles. Therefore, the this study aimed to investigate and compare the palatability changes of VL muscle from different quality grades $\left(1^{+}\right.$and 1$)$ during $28 \mathrm{~d}$ of postmortem wet-aging with the well-characterized LT muscle of Hanwoo steer in order to improve the utilization of the VL muscle as a steak.

\section{Materials and Methods}

\section{Muscle samples and preparation}

A total of $10 \mathrm{LT}$ and $10 \mathrm{VL}$ muscles from a total of 10 Hanwoo steers $\left(1^{+}\right.$quality grade, $\mathrm{n}=5 ; 1$ quality grade, $\left.\mathrm{n}=5\right)$ were used in this study. At $24 \mathrm{~h}$ postmortem, muscle samples were removed from the left side of Hanwoo steers after carcass quality grading by the Korea Institute of Animal Products Quality Evaluation (KAPE, 2017). The KAPE provided the marbling scores and beef quality grades of each carcass. The LT and VL muscles of each animal were cut into six sections (one section for the meat quality measurements; five sections for the aging experiments), respectively. Each section within 
each muscle was randomly assigned to one of the five aging periods $(0,7,14,21$, and $28 \mathrm{~d})$ and meat quality measurements. A total of 80 muscle sections for wet-aging ( 10 animals $\times 2$ muscles $\times 4$ aging periods; except of $0 \mathrm{~d}$ ) were placed individually in nylon-polyethylene bags (thickness $90 \mu \mathrm{m}$, oxygen transmission rate $50 \mathrm{~cm}^{3} / \mathrm{m}^{2} / 24 \mathrm{~h}$ ). Muscle sections were then packaged using a vacuum packaging machine (Leepack, Hanguk Electronics, Incheon, Korea), and the vacuum level was $2.5 \mathrm{kPa}$. Muscle sections were then wet-aged at $2^{\circ} \mathrm{C}$ for $7,14,21$, and $28 \mathrm{~d}$. At each aging period, sections were removed from the vacuum package and cut into three steak-size cuts of $1.5 \mathrm{~cm}$ thick (one cut for cooking loss and WBS analysis; two cuts for sensory quality analysis), and then were frozen and stored at $-20^{\circ} \mathrm{C}$.

\section{Meat quality measurements and chemical analysis}

Ultimate muscle $\mathrm{pH}$ was measured at $24 \mathrm{~h}$ postmortem in the middle part of the LT and VL muscles using a portable $\mathrm{pH}-$ and temperature-measuring instrument with a penetration probe (Testo 206-pH2, Testo AG, Lenzkirch, Germany). At $24 \mathrm{~h}$ postmortem, muscle surfaces were allowed to bloom at $4{ }^{\circ} \mathrm{C}$ in a cold room for $30 \mathrm{~min}$, and then meat color values were recorded using a chromameter (CR-400, Minolta Camera Co., Osaka, Japan). The color values, including lightness ( $\left.\mathrm{L}^{*}\right)$, redness $\left(a^{*}\right)$, and yellowness $\left(b^{*}\right)$, were expressed according to the recommendations of the Commission Internationale de l'Eclairage (1978).

The IMF, collagen, and myoglobin contents were measured using samples from the LT and VL muscles at $24 \mathrm{~h}$ postmortem. The IMF content was determined by the Soxhlet method (AOAC, 2012) using a solvent extraction system. The collagen content in muscle samples was measured using the hydroxyproline content as a calibration curve (Cross et al., 1973). The myoglobin content was calculated based on the absorbance value (Tang et al., 2004).

\section{Cooking loss and WBS analysis}

At each aging period, cooking loss and WBS were measured based on Honikel (1998). Cooked sample preparation for cooking loss and WBS analysis was the same. Samples of the LT and VL muscles were first placed inside a thin polyethylene bag and then placed in a continuously heated water-bath until the final internal temperature reached $71^{\circ} \mathrm{C}$. Beef samples were weighed before and after cooking to calculate the percentage of cooking loss (Honikel, 1998). For analysis of WBS, six to ten cores $\left(1.27 \mathrm{~cm}^{2}\right.$ diameter) were used. The WBS force was measured using an Instron Universal Testing Machine (Model 1011; Instron Corp., Canton, USA) equipped with a Warner-Bratzler blade operating at load capacity $10 \mathrm{kN}$ with a crosshead speed of $200 \mathrm{~mm} / \mathrm{min}$ (American Meat Science Association, 1995).

\section{Trained sensory panel analysis}

For the sensory quality analysis, a total of 200 beef samples were evaluated (10 animals $\times 2$ muscles $\times 5$ aging periods $\times 2$ replicates) during 34 sessions (5 to 6 samples for 1 session). All panel training sessions and sensory evaluations were performed at Kyungpook National University (KNU), and the human ethics approval was granted by the Bioethics Committee of KNU (protocol number: 2019-0027). Eleven panelists were trained according to previously published procedures (American Meat Science Association, 1995; Meilgaard et al., 1991). Each panelist evaluated the cooked beef samples of each muscle, quality grade, and aging time for tenderness (1 to 9 ; not at all tender to extremely tender), juiciness (1 to 9; extremely dry to extremely juicy), and flavor intensity (1 to 9; no beef flavor to full beef flavor) using a 9-point hedonic scale. 


\section{Statistical analysis}

In order to compare meat quality, chemical traits, and sensory quality between muscle locations, beef quality grades, and aging time, the general linear model (GLM) procedure in SAS software (2014) was performed to elucidate any associations. Significant differences in the least squares means (LSM) of investigated parameters between the groups were compared by the probability difference (PDIFF) option at $\mathrm{p} \leq 0.05$. All data were presented as LSM and standard errors.

\section{Results}

\section{Comparison of meat quality and chemical characteristics}

Table 1 shows the comparison of meat quality and chemical characteristics between the LT and VL muscles from different quality grades at $24 \mathrm{~h}$ postmortem. The LT muscle showed a lower muscle $\mathrm{pH}$ compared with the $\mathrm{VL}$ muscle $(\mathrm{p}<0.05)$, although no significant difference was observed between the LT muscle from $1^{+}$grade $\left(\mathrm{LT}-1^{+}\right)$carcass and the VL muscle from $1^{+}$grade $\left(\mathrm{VL}-1^{+}\right)$carcass (5.36 vs. 5.47 , respectively). Lightness value was higher in the $\mathrm{LT}-1^{+}$compared to the other groups $(\mathrm{p}<0.05)$ possibly due to a higher number of smaller marbling fleck in the LT- $1^{+}$(Lee et al., 2019), whereas there were no differences in redness and yellowness among the groups ( $\mathrm{p}>0.05$ ). As expected, the LT $-1^{+}$grade group showed the highest IMF content compared to the other groups $(\mathrm{p}<0.05)$ and no difference was detected between the two grades within the VL muscle $(10.8 \%$ vs. $11.1 \%, \mathrm{p}>0.05)$. Collagen $(0.31 \%$ vs. $0.18 \%, \mathrm{p}<0.05)$ and myoglobin $(6.97 \mathrm{vs.} 6.39 \mathrm{mg} / \mathrm{g}, \mathrm{p}<0.05)$ contents were higher in the VL-1 group than the LT-1 $1^{+}$group.

\section{Comparison of cooking loss and WBS value during postmortem aging}

The cooking loss values in the LT and VL muscles from different quality grades during postmortem wet-aging are shown in Table 2. At each aging period, the LT muscle exhibited a lower cooking loss compared to the VL muscle ( $<<0.05$ ). Noticeable differences were observed between the LT- $1^{+}$and VL- $1^{+}$groups aged $0(14.9 \%$ vs. $28.7 \%, \mathrm{p}<0.05)$ and $14(18.3 \%$ vs. $31.8 \%$, $\mathrm{p}<0.05) \mathrm{d}$. After aging for $14 \mathrm{~d}$, a significant increase was observed within the LT $-1^{+}$muscle $(\mathrm{p}<0.05)$, and the LT $-1^{+}$samples

Table 1. Comparison of meat quality and chemical characteristics between longissimus thoracis (LT) and vastus lateralis (VL) muscles from different quality grades (1+ and 1$)$ at $24 \mathrm{~h}$ postmortem

\begin{tabular}{|c|c|c|c|c|c|c|c|c|}
\hline \multirow{2}{*}{$\begin{array}{l}\text { Muscle } \\
\text { Grade }\end{array}$} & \multicolumn{2}{|c|}{ LT muscle } & \multicolumn{2}{|c|}{ VL muscle } & \multirow{2}{*}{ SEM } & \multicolumn{3}{|c|}{ Level of significance } \\
\hline & $1^{+}$ & 1 & $1^{+}$ & 1 & & M & G & $\mathrm{M} \times \mathrm{G}$ \\
\hline Muscle $\mathrm{pH}_{\mathrm{u}}$ & $5.36^{\mathrm{b}}$ & $5.37^{\mathrm{b}}$ & $5.47^{\mathrm{ab}}$ & $5.50^{\mathrm{a}}$ & 0.10 & $*$ & NS & NS \\
\hline Lightness (L*) & $41.1^{\mathrm{a}}$ & $39.2^{\mathrm{b}}$ & $36.6^{\mathrm{c}}$ & $37.1^{\mathrm{c}}$ & 0.57 & $* * *$ & NS & $*$ \\
\hline Redness $\left(\mathrm{a}^{*}\right)$ & 22.3 & 22.1 & 23.5 & 23.1 & 0.60 & NS & NS & NS \\
\hline Yellowness $\left(b^{*}\right)$ & 10.6 & 9.94 & 9.98 & 9.73 & 0.37 & NS & NS & NS \\
\hline \multicolumn{9}{|l|}{ Chemical analysis } \\
\hline Intramuscular fat (\%) & $19.8^{\mathrm{a}}$ & $15.9^{\mathrm{b}}$ & $10.8^{\mathrm{c}}$ & $11.1^{\mathrm{c}}$ & 1.52 & *** & NS & NS \\
\hline Collagen (\%) & $0.18^{\mathrm{b}}$ & $0.13^{b}$ & $0.39^{\mathrm{a}}$ & $0.31^{\mathrm{a}}$ & 0.05 & $* * *$ & NS & NS \\
\hline Myoglobin (mg/g) & $6.39^{b}$ & $6.29^{b}$ & $6.84^{\mathrm{a}}$ & $6.97^{\mathrm{a}}$ & 0.28 & $*$ & NS & NS \\
\hline
\end{tabular}

${ }^{\mathrm{a}-\mathrm{c}}$ Different superscripts in the same row represent significant differences $(\mathrm{p}<0.05)$.

${ }^{*} \mathrm{p}<0.05,{ }^{* * *} \mathrm{p}<0.001$.

M, muscle; G, grade; NS, not significant. 
Table 2. Comparison of cooking loss between longissimus thoracis (LT) and vastus lateralis (VL) muscles from different quality grades $\left(1^{+}\right.$and 1$)$ during postmortem wet-aging

\begin{tabular}{|c|c|c|c|c|c|}
\hline \multirow{2}{*}{ Aging period } & \multicolumn{2}{|c|}{ LT muscle } & \multicolumn{2}{|c|}{ VL muscle } & \multirow{2}{*}{ SEM } \\
\hline & $1+$ & 1 & $1+$ & 1 & \\
\hline 0 & $14.9^{\mathrm{bx}}$ & $16.7^{\text {by }}$ & $28.7^{\text {ay }}$ & $29.5^{\mathrm{az}}$ & 0.80 \\
\hline 7 & $16.4^{\mathrm{bx}}$ & $18.6^{\text {by }}$ & $25.0^{\mathrm{ax}}$ & $24.5^{\mathrm{ay}}$ & 0.90 \\
\hline 14 & $18.3^{\mathrm{dy}}$ & $22.4^{\mathrm{cz}}$ & $31.8^{\mathrm{az}}$ & $29.2^{\mathrm{bz}}$ & 0.81 \\
\hline 21 & $20.7^{\mathrm{bz}}$ & $21.4^{\mathrm{bz}}$ & $26.7^{\operatorname{axy}}$ & $24.2^{\text {ay }}$ & 0.98 \\
\hline 28 & $21.6^{\mathrm{bz}}$ & $22.2^{\mathrm{bz}}$ & $28.4^{\text {ay }}$ & $28.5^{\mathrm{az}}$ & 1.00 \\
\hline
\end{tabular}

${ }^{a-d}$ Different superscripts in the same row represent significant differences $(p<0.05)$.

${ }^{x-z}$ Different superscripts in the same column represent significant differences $(p<0.05)$.

at $7 \mathrm{~d}$ of aging showed a lower cooking loss compared to the samples at 14 and $28 \mathrm{~d}$ of aging $(16.4 \%, 18.3 \%$, and $21.6 \%$, respectively). Moreover, the cooking loss result of the LT-1 samples at different aging periods exhibited a similar tendency as the $\mathrm{LT}-1^{+}$samples. Unlike the LT muscle, the VL muscle did not exhibit an increase in cooking loss with increasing aging time although a significant difference was observed within the $1^{+}$or 1 sample in the VL muscle $(p<0.05)$.

Within the LT muscle at each aging period, the 1 grade showed a higher WBS value compared to the $1^{+}$grade $(\mathrm{p}<0.05)$ except on $28 \mathrm{~d}$, and no significant difference was observed at $28 \mathrm{~d}$ of aging between the grades (39.4 vs. $36.5 \mathrm{~N}$, respectively) (Fig. 1). Within the $\mathrm{LT}-1^{+}$, the WBS value at $0 \mathrm{~d}$ of aging was higher than value at $14 \mathrm{~d}$ of aging $(56.5 \mathrm{vs} .35 .5 \mathrm{~N}, \mathrm{p}<0.05)$ and there was a no difference within the $1^{+}$grade of LT muscle after $14 \mathrm{~d}$ of aging ( $\left.>00.05\right)$. Additionally, WBS value of the LT-1 group at $0 \mathrm{~d}$ of aging was a higher than that of the LT-1 group at $21 \mathrm{~d}$ of aging $(68.4$ vs. $51.7 \mathrm{~N}, \mathrm{p}<0.05)$. Within the VL muscle, there were no differences between the grades at each aging period ( $p>0.05$ ). The WBS value of the VL-1 group at $0 \mathrm{~d}$ of aging was a higher than that of the VL-1 group after $21 \mathrm{~d}$ of aging $(\mathrm{p}<0.05)$, and similar tendency was observed in the VL-

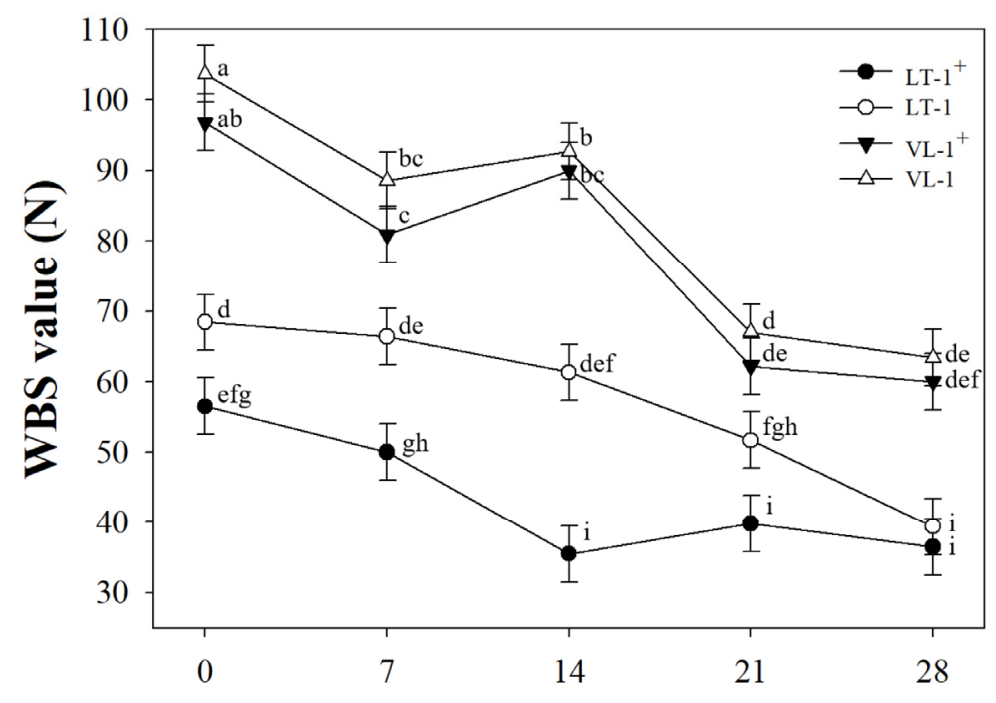

Aging time (d)

Fig. 1. Comparison of Warner-Bratzler shear force (WBS) value between longissimus thoracis (LT) and vastus lateralis (VL) muscles from different quality grades $\left(\mathbf{1}^{+}\right.$and $\left.\mathbf{1}\right)$ during postmortem wet-aging. Bars indicate standard errors of means. ${ }^{a-i}$ Different superscripts represent significant differences $(p<0.05)$. 
$1^{+}$group. Moreover, no significant differences were observed in the WBS value among samples from the LT-1 group at $0 \mathrm{~d}$ of aging and samples from the VL muscles after $21 \mathrm{~d}$ of aging.

\section{Comparison of sensory quality characteristics during postmortem aging}

Sensory quality characteristics, including tenderness, juiciness, and flavor intensity, in the LT and VL muscles from different quality grades during postmortem wet-aging are shown in Fig. 2. Within the LT muscle, the 1 grade showed a lower value of tenderness compared to the $1^{+}$grade at each aging period $(\mathrm{p}<0.05)$ except on $28 \mathrm{~d}$. After $14 \mathrm{~d}$ of aging, the $1^{+}$or 1 grades displayed higher sensory tenderness scores compared to the $1^{+}(7.41$ vs. $6.23, \mathrm{p}<0.05)$ or $1(6.42$ vs. $5.21, \mathrm{p}<0.05)$ grades at $0 \mathrm{~d}$ of aging, respectively. For the VL muscle, no differences were detected in tenderness scores between the grades from 0 to $14 \mathrm{~d}$ of aging $(\mathrm{p}>0.05)$. Higher tenderness scores were observed within each grade in the same muscle $(\mathrm{p}<0.05)$ aged $21 \mathrm{~d}$ compared to $0 \mathrm{~d}$. On the contrary, steaks from the LT-1 at $0 \mathrm{~d}$ of aging showed a similar tenderness score compared to steaks from the VL- $1^{+}$after both 21 and $28 \mathrm{~d}$ of aging $(5.21,4.89$, and $4.84, \mathrm{p}>0.05$ ). Like sensory tenderness, the 1 grade showed a lower juiciness score compared to the $1^{+}$grade at each aging period from 0 to $21 \mathrm{~d}$ in the LT muscle $(\mathrm{p}<0.05)$. After $21 \mathrm{~d}$ of aging, juiciness was higher than at $0 \mathrm{~d}$ of aging in the LT- 1 muscle $(\mathrm{p}<0.05)$; whereas, no differences were found between the grades within the VL muscle at each aging period $(\mathrm{p}>0.05)$. Moreover, there was no significant difference between at 0 and $28 \mathrm{~d}$ of aging in the VL- $1^{+}$group (3.33 vs. 3.67), although the VL-1 at $28 \mathrm{~d}$ showed a higher score than the VL-1 at $0 \mathrm{~d}(3.84$ vs. $2.59, \mathrm{p}<0.05)$. For flavor intensity, the LT- $1^{+}$group at $14 \mathrm{~d}$ of aging had a higher score compared to the same group at $0 \mathrm{~d}$ of aging (6.71 vs. 5.67, p<0.05), and similar tendency was observed in the LT- 1 group. In the VL- $1^{+}$group, no difference was observed between aging periods $(\mathrm{p}>0.05)$. Conversely, the flavor intensity score of the LT-1group at $0 \mathrm{~d}$ of aging was similar to that assigned to the $\mathrm{VL}-1^{+}$group at $7 \mathrm{~d}$ of aging ( 4.78 vs. $4.26, \mathrm{p}>0.05$ ).

\section{Discussion}

The distinct differences between muscles from the same animal possibly by not only in the contractile behavior but also in the biochemical and morphological characteristics of muscle fiber (Nair et al., 2019). These muscle specificities can contribute to variations in quality of fresh meat and palatability of cooked meat (Lee et al., 2018). The VL muscle is part of the quadriceps femoris muscle group, which includes the $\mathrm{VL}$, vastus medialis, vastus intermedius, and rectus femoris muscles (King et al., 2009). This muscle has a variety of functionally different fiber types and pronounced changes in exercise intensity (Staron et al., 2000). Due to functional characteristics of the VL muscle, higher composition of type I fiber, collagen, and myoglobin were observed compared to the LT muscle (Kolle et al., 2004) or the other muscles (Stolowski et al., 2006). In the current study, the VL muscle exhibited a lower IMF content and higher collagen content compared to the LT muscle at $24 \mathrm{~h}$ postmortem. Especially, the collagen content of the VL- $1^{+}$muscle was approximately 2.2 times greater than that of the LT $-1^{+}$muscle $(\mathrm{p}<0.05)$. Additionally, the $1^{+}$and 1 grades from VL muscle showed a darker cut-surface and higher myoglobin content compared to the LT muscle $(\mathrm{p}<0.05)$. These finding highlight the distinct biochemical characteristics between these muscles, especially in the contents of IMF and collagen, and it is possible that these muscles respond differently to wet-aging.

Water holding capacity (WHC) may not be improved by postmortem aging (Modzelewska-Kapitula et al., 2015). In this study, the cooking loss of steaks from the LT muscle tended to increase gradually from 0 to $28 \mathrm{~d}$ of aging. A comparable trend of cooking loss changes during postmortem aging was published by Wyrwisz et al. (2016). Anderson et al. (2012) 

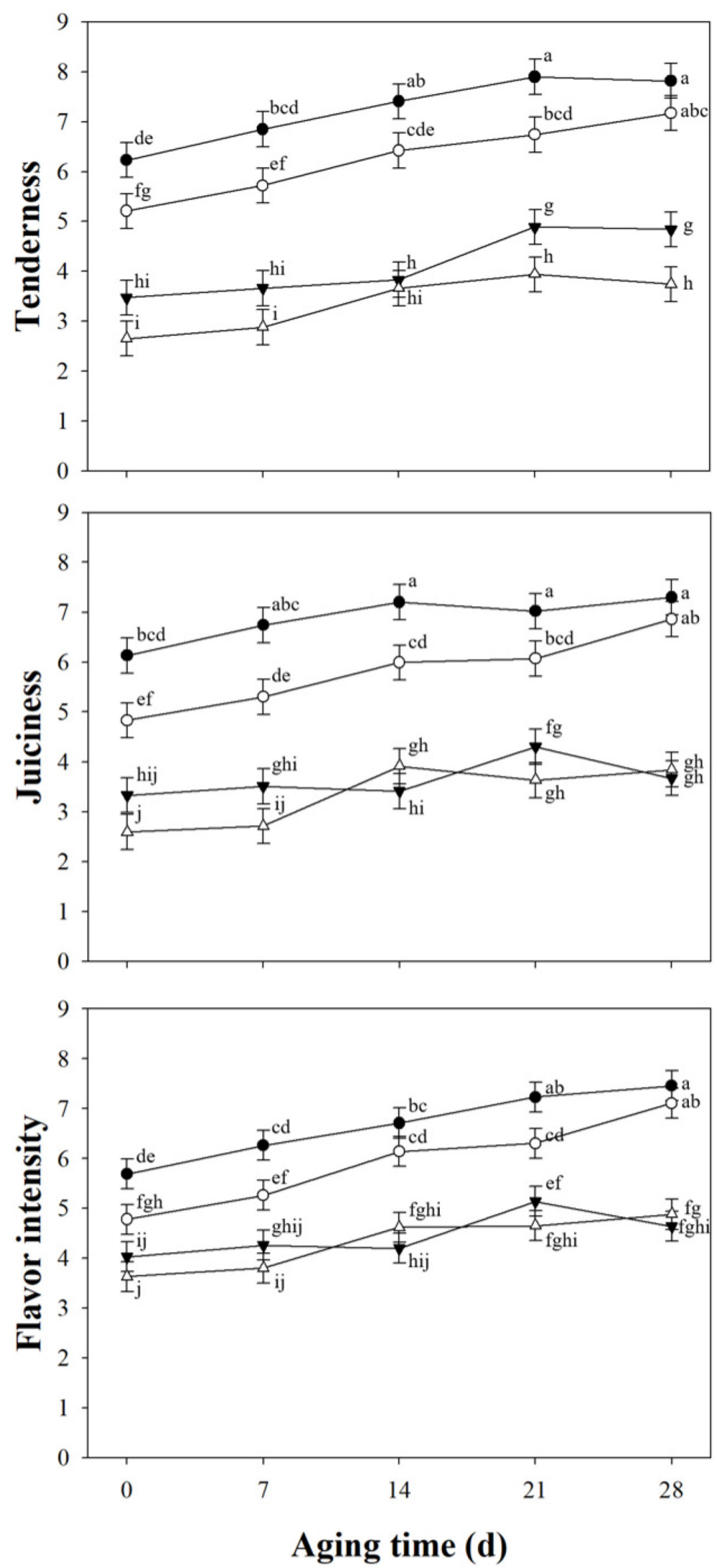

Fig. 2. Comparison of palatability characteristics, including tenderness, juiciness, and flavor intensity, between longissimus thoracis (LT and vastus lateralis (VL) muscles from different quality grades $\left(1^{+}\right.$and 1$)$ during postmortem wet-aging. Bars indicate standard errors of means. ${ }^{a-j}$ Different superscripts represent significant differences $(p<0.05)$. 
reported no significant changes in cooking loss of the $\mathrm{VL}$ and vastus intermedius muscles during 1 to $14 \mathrm{~d}$ of aging. Similarly, in the current study, there was no significant difference in the VL muscles between 0 and $28 \mathrm{~d}$ of aging. On the other contrary, the VL muscle with a higher collagen content showed a greater cooking loss during the aging period in comparison to the LT muscle with lower collagen content. This result is justified because the collagen concentration is negatively correlated with the WHC in bovine muscle (Modzelewska-Kapitula et al., 2015). However, the effect of quality grade on cooking loss was somewhat limited in the LT or VL muscle.

The LT $-1^{+}$muscle harboring a higher IMF content exhibited a lower WBS value and a higher tenderness score compared to the LT-1 muscle harboring a lower IMF content at $24 \mathrm{~h}$ postmortem $(\mathrm{p}<0.05)$. However, difference of the IMF content between the grades in the LT muscles showed a tendency distinct from the VL muscle, and so similar IMF contents were observed between the quality grades in the VL muscle $(\mathrm{p}>0.05)$. For this reason, no differences were observed in the WBS and sensory tenderness between the grades in the VL muscle at $0 \mathrm{~d}$ of aging. During wet-aging, steaks from the LT and VL muscles demonstrated significant improvements in tenderness. In the LT muscle, sensory tenderness improved from 0 to $14 \mathrm{~d}$ of aging. In the VL muscle, improved values of WBS and sensory tenderness were observed after $21 \mathrm{~d}$ of aging when compared with the corresponding values at $0 \mathrm{~d}$ of aging, although the changes in WBS and tenderness were not linear and consistent. However, wet-aging beyond 14 and $21 \mathrm{~d}$ did not improve sensory tenderness of the LT and VL muscles, respectively. These results on required aging time for tenderness improvement corroborate previous studies (Anderson et al., 2012; Nair et al., 2019; Stolowski et al., 2006) that steaks from the longissimus lumborum muscle generally needed a shorter aging time to improve tenderness compared to steaks from the other muscles. Stolowski et al. (2006) demonstrated that a longer aging time was required for the VL muscle compared to the longissimus dorsi and semimembranosus muscles. These differences between muscles during aging is mainly due to variations in the connective tissue protein content, IMF content, and postmortem proteolysis (Nair et al., 2019). Especially, greater collagen content in the VL muscle than in the other muscles is the most important factor contributing to the variations in tenderness during the aging period (King et al., 2009). On the other hand, Bratcher et al. (2005) suggested that beef loins of lower quality grade needed longer aging times compared to beef loins of upper quality grades in the USA. In the current study, there was no marked difference between the $1^{+}$and 1 grades in aging time required for sensory tenderness within each muscle in Hanwoo steer. Additionally, the VL- $1^{+}$steaks aged for $21 \mathrm{~d}$ and the LT-1 steaks at $24 \mathrm{~h}$ postmortem exhibited similar tenderness score and WBS value to each other.

Considerable improvements in juiciness and flavor can also occur during wet-aging period possibly due to structural changes of muscles through the action of endogenous proteases (Huff-Lonergan and Lonergan, 2005). In the current study, juiciness and flavor improved significantly in the LT steaks from 0 to $14 \mathrm{~d}$ of aging like sensory tenderness. Conversely, steaks from the VL- $1^{+}$muscle received similar scores in juiciness and flavor between 0 and $28 \mathrm{~d}$ of aging although these traits slightly improve in the VL-1 steak from 0 to $28 \mathrm{~d}$ of aging. A result reported by Anderson et al. (2012) proved similar tendencies for juiciness and flavor in the VL muscle and no differences were detected during aging periods. Thus, the effect of aging time on juiciness and flavor in the VL muscle is somewhat limited unlike tenderness.

\section{Conclusion}

In the current study, the sensory tenderness of cooked beef improved as aging time increased, and the required times to improve tenderness were $14 \mathrm{~d}$ of aging in the LT muscle. Additionally, trained panelists did not distinguish the difference in tenderness between the VL- $1^{+}$steaks aged for $21 \mathrm{~d}$ and the LT-1 steaks at $24 \mathrm{~h}$ postmortem, although the LT steaks were 
tenderer compared to the VL steaks at each aging period due to a higher concentration of collagen in the VL muscle. Moreover, the VL- $1^{+}$steak was tenderer than the VL-1 steak after $21 \mathrm{~d}$ of aging, whereas no differences were detected between the quality grades at $24 \mathrm{~h}$ postmortem. Taken together, our results indicated that the VL muscle should be aged for at least $21 \mathrm{~d}$ to improve consumer preference and utilization of this muscle. Considering the tenderness, using a higher quality grade for aging is also more useful in the VL muscle unlike the LT muscle.

\section{Conflict of Interest}

The authors declare no potential conflict of interest.

\section{Acknowledgement}

This research was supported by the National Research Foundation of Korea (NRF-2017R1D1A3B03029840).

\section{Author Contributions}

Conceptualization: Yun Y, Kwon K, Kang S. Data curation: Yun Y, Choi YM. Formal analysis: Yun Y. Methodology: Lee B. Validation: Choi YM. Investigation: Lee B. Writing - original draft: Yun Y, Lee B, Choi YM. Writing - review \& editing: Yun Y, Lee B, Kwon K, Kang S, Oh E, Choi YM.

\section{Ethics Approval}

The human ethics approval was granted by Bioethics Committee of Kyungpook National University (protocol number: 2019-0027).

\section{References}

American Meat Science Association [AMSA]. 1995. Research guidelines for cookery, sensory evaluation, and instrumental tenderness measurements of fresh meat. National Livestock and Meat Board, Chicago, IL, USA.

Anderson MJ, Lonergan SM, Fedler CA, Prusa KJ, Binning JM, Huff-Lonergan E. 2012. Profile of biochemical traits influencing tenderness of muscles from the beef round. Meat Sci 91:247-254.

AOAC. 2012. Official methods of analysis of AOAC international. $19^{\text {th }}$ ed. AOAC International, Gaithersburg, MD, USA. p 931.

Berg J, Kim YHB, Legako JF, Martini S, Lee J, Ebner P, Zuelly SMS. 2018. Dry-aging improves meat quality attributes of grass-fed beef loins. Meat Sci 145:285-291.

Bratcher CL, Johnson DD, Littell RC, Gwartney BL. 2005. The effects of quality grade, aging, and location within muscle on Warner-Bratzler shear force in beef muscles of locomotion. Meat Sci 70:279-284.

Honikel KO. 1998. Reference methods for the assessment of physical characteristics of meat. Meat Sci 49:447-457.

Huff-Lonergan E, Lonergan SM. 2005. Mechanisms of water-holding capacity of meat: The role of postmortem biochemical and structural changes. Meat Sci 71:194-204. 
Hulankova R, Kamenik J, Salakova A, Zavodsky D, Borilova G. 2018. The effect of dry aging on instrumental, chemical and microbiological parameters of organic beef loin muscle. LWT-Food Sci Technol 89:559-565.

International Commission on Illumination. 1978. Recommendations on Uniform Color Spaces, Color-Differences Equations, Psychrometic Color Terms (Supplement No. 2). CIE Publication No. 15 (E1.3.1). International Commission on Illumination, Paris, France.Cross HR, Carpenter ZL, Smith GC. 1973. Effects of intramuscular collagen and elastin on bovine muscle tenderness. J Food Sci 38:998-1003.

King DA, Shackelford SD, Wheeler TL, Pfeiffer KD, Mehaffey JM, Miller MF, Nickelson R, Koohmaraie M. 2009. Consumer acceptance and steak cutting yields of beef top sirloin and knuckle subprimals. Meat Sci 83:782-787.

Kolle BK, McKenna DR, Savell JW. 2004. Methods to increase tenderness of individual muscles from beef rounds when cooked with dry or moist heat. Meat Sci 68:145-154.

Koohmaraie M, Kent MP, Shackelford SD, Veiseth E, Wheeler TL. 2002. Meat tenderness and muscle growth: Is there any relationship? Meat Sci 62:345-352.

Korea Institute of Animal Products Quality Evaluation [KAPE]. Beef. Available from: http://www.ekapepia.or.kr/view/ eng/system/beef.asp. Accessed at Feb 1, 2017.

Lee B, Yoon S, Choi YM. 2019. Comparison of marbling fleck characteristics between beef marbling grades and its effect on sensory quality characteristics in high-marbled Hanwoo steer. Meat Sci 152:109-115.

Lee Y, Lee B, Kim HK, Yun YK, Kang SJ, Kim KT, Kim BD, Kim EJ, Choi YM. 2018. Sensory quality characteristics with different beef quality grades and surface texture features assessed by dented area and firmness, and the relation to muscle fiber and bundle characteristics. Meat Sci 145:195-201.

Lepper-Blilie AN, Berg EP, Buchanan DS, Berg PT. 2016. Effects of post-mortem aging time and type of aging on palatability of low marbled beef loins. Meat Sci 112:63-68.

Meilgaard M, Civille GV, Carr BT. 1991. Affective tests: Consumer tests and in-house panel acceptance tests. In Sensory evaluation techniques. Meilgaard M, Civille GV, Carr BT (ed). CRC Press, Boca Raton, FL, USA. pp 201-235.

Modzelewska-Kapitula M, Kwiatkowska A, Jankowska B, Dabrowska E. 2015. Water holding capacity and collagen profile of bovine $m$. infraspinatus during postmortem ageing. Meat Sci 100:209-216.

Nair MN, Canto ACVCS, Rentfrow G, Suman SP. 2019. Muscle-specific effect of aging on beef tenderness. LWT-Food Sci Technol 100:250-252.

SAS. 2014. SAS/STAT software for PC. Release 9.4, SAS Institute Inc., Cary, NC, USA.

Smith GC, Berry BW, Savel JW, and Cross HR. 1988. USDA maturity indices and palatability of beef rib steaks. J Food Qual 11:1-13.

Staron RS, Hagerman FC, Hikida RS, Murray TF, Hostler DP, Crill MT, Ragg KE, Toma K. 2000. Fiber type composition of the vastus lateralis muscle of young men and women. J Histochem Cytochem 48:623-629.

Stolowski GD, Baird BE, Miller RK, Savell JW, Sams AR, Taylor JF, Sanders JO, Smith SB. 2006. Factors influencing the variation in tenderness of seven major beef muscles from three Angus and Brahman breed crosses. Meat Sci 73:475-483.

Tang J, Faustman C, Hoagland TA. 2004. Krzywicki revisited: Equations for spectrophotometric determination of myoglobin redox forms in aqueous meat extracts. J Food Sci 69:C717-C720.

Wyrwisz J, Moczkowska M, Kurek M, Stelmasiak A, Poltorak A, Wierzbicka A. 2016. Influence of 21 days of vacuum-aging on color, bloom development, and WBSF of beef semimembranosus. Meat Sci 122:48-54. 